\title{
Research on the Phenomenon of Internet Celebrity Design
}

\author{
Jida $\mathrm{Li}^{1}$ \\ ${ }^{1}$ Acadamy of Fine Arts, Hunan Normal University, Changsha, Hunan, China \\ *Email:821583081@qq.com
}

\begin{abstract}
To study the characteristics and causes of Internet celebrity design and probes into the design meanings behind it. Starting from the definition of Internet celebrity design itself, this paper points out the relationship between Internet celebrity and design, analyzes the phenomenon of Internet celebrity design, the characteristics and causes. Internet celebrity design represents a new trend of design development in the era of mass media, which relies on Internet technology to promote the design in multi-dimensional interactive promotion. It not only inherits the gene of Internet celebrity in exchange for attention in a novel and weird way, but also brings new changes and thinking to the design industry through its unique design features and forms.
\end{abstract}

Keywords : Internet celebrity design, communication, forms, aesthetics

\section{ANALYSIS OF INTERNET CELEBRITY DESIGN}

\subsection{Definition of Internet Celebrity Design}

As early as 1994, when the Internet was just rising in China, the word " Internet celebrity " has quietly appeared in the public field of vision [1]. Today, Internet celebrity not only represents a unique social group, but also becomes a prominent social phenomenon [2], which has established extensive contacts with all aspects of people's daily life.

What is Internet celebrity? From the perspective of economics, Internet celebrity is a person who manages his own image through the Internet and has the ability of commercial cash flow; from the perspective of communication, Internet celebrity is a person who uses the Internet to spread information; from the perspective of aesthetics, Internet celebrity is an aesthetic subject with unique aesthetic tastes. Although there are some inevitable differences in the understanding of Internet celebrity from different directions, the meaning of the word "Internet celebrity" is too narrow to be explained. As a matter of fact, with the development of Internet celebrity today, it has already broken away from the category of people and widely penetrated into people, things and other aspects.
Today, with the wide spread of Internet celebrity, it has had an impact on many fields such as economics, sociology, politics, communication, aesthetics and so on. As a discipline closely combined with social life, design science has been strongly impacted by Internet celebrity. Under the joint promotion of economy, culture, politics and technology, Internet celebrity design came into being. Internet celebrity design is a popular design work through the Internet channel. It represents the new development trend of multi-dimensional interactive promotion of design relying on Internet technology in the era of mass media.

\subsection{Internet Celebrity Design Phenomenon}

In recent years, in many design fields such as graphic design, interior design, industrial design, architectural design and so on, an Internet celebrity style has sprung up. A large number of Internet celebrity designs with unique style and innovation are competing to appear in the market and quickly get the attention of consumers.

For example, Beijing Palace Museum Cultural and creative products (see Figure 1), has become a super Internet celebrity with 5.42 million fans and an annual sales volume of 1 billion since the official sales online store of Taobao was launched in 2010. Beijing Palace Museum has changed it's serious attitude of the former products, and began to become "unorthodox". The Palace Museum not only attracts numerous fans through various 
kinds of cute interaction, but also drives the collective cute selling trend of museums and other cultural and Museum institutions across the country [3].

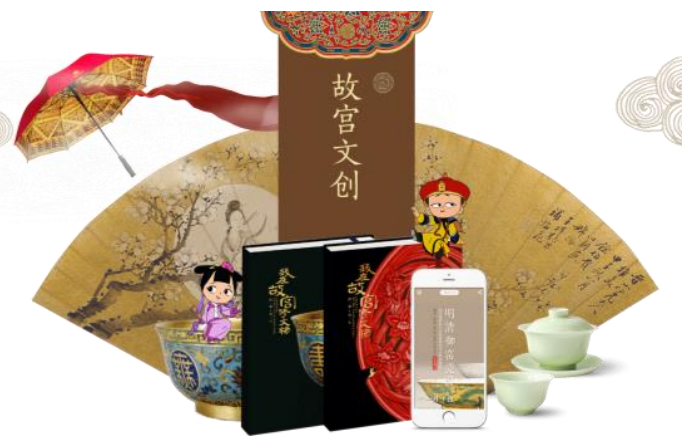

Figure 1 Beijing forbidden city cultural and creative design

WENHEYOU restaurant (see Figure 2) uses the twisted spatial layout and shabby and mottled old buildings embedded in a modern shopping center, making it out of place with the surrounding buildings. No matter the spatial layout or decoration layout, WENHEYOU tries to restore the scene of Changsha Street in the 1980s and stay in the shopping center Among them, it's like walking back to the streets of old Changsha in the 1980s, and a sense of intimacy arises spontaneously [4]. With its unique design language, WENHEYOU has attracted tourists from all over the country to experience. In the hot holidays, the number of tables even reaches tens of thousands, and the daily turnover reaches millions.

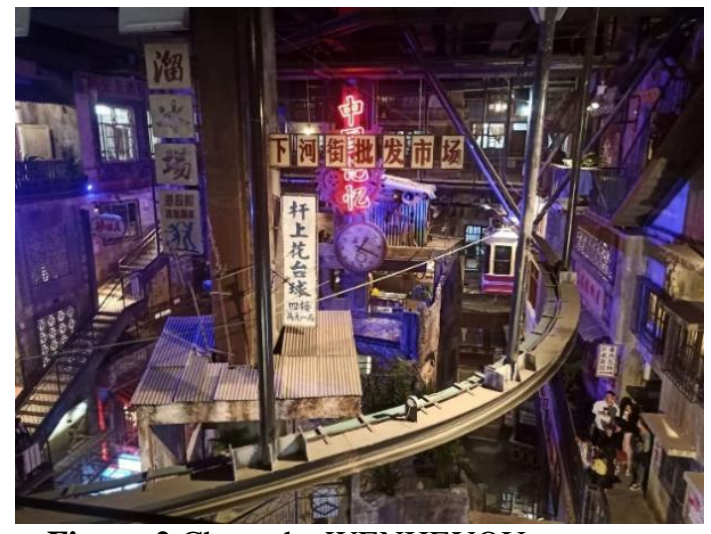

Figure 2 Changsha WENHEYOU restaurant

Internet celebrity design shapes its own design image with novel formal language, and forms Internet celebrity effect with the help of mass media promotion, which makes it become the target of many audiences. In this cultural context, the term " Internet celebrity design" has long been separated from the original derogatory, narrow, vulgar and minority meaning, and even gradually become the pronoun of trend, fashion, youth and creativity.

\section{CHARACTERISTICS OF INTERNET CELEBRITY}

\subsection{Short Design Prevalent Time}

Design timeliness refers to the effective duration of design works occupying the market, which can be divided into three stages: rising stage, flourishing stage and declining stage. Compared with traditional design, Internet celebrity design depends more on the timeliness of prevalence. Design works become Internet celebrities through publicity, which relies on catering to the needs of the audience for novelty and novelty, and obtaining attention by using novel and grotesque forms of expression, so as to win the audience market. But the prevalent status of any design is not constant, and the popularity of design works will inevitably face the problem of design timeliness. When new and more attractive forms appear in the market, those design works that only rely on the form to obtain attention and become Internet celebrity are experiencing a brief boom. After the period, it began to fade out of the audience's vision quickly.

\subsection{Younger Design Audience}

According to the statistical report on China's Internet Development released by China Internet Network Information Center (CNNIC), as of March 28, 2020, the number of Internet users in China is 904 million, and the Internet penetration rate is $64.5 \%$. According to the age structure of Internet users in China (see figure 3), Internet users aged 10-39 accounted for $62.6 \%$ respectively, which was significantly higher than other age groups.

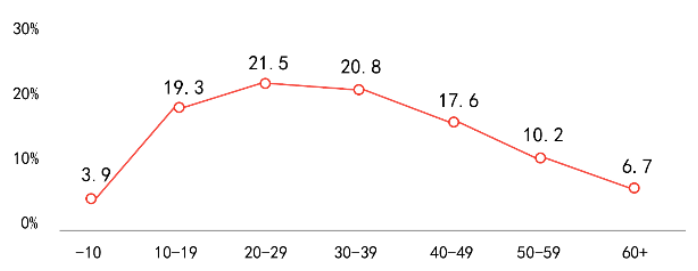

Figure 3 Age structure of internet users in China

This shows that the Internet is mainly young users, they can better offset the boundaries of technology, and are good at using the network to obtain information, but also can quickly accept new things. Through the multiple communication of social activities and social media, the design works that meet the aesthetic standards of this group and meet their functional needs can quickly become the favorite of the public, so as to attract more attention and get more extensive attention with the identity of Internet celebrity design.

\subsection{Heterogeneity of Design Works}

Heterogeneity of design works refers to the pursuit of obvious differences with other design works in design 
form, connotation, service and price. The purpose is to create a unique expression language and establish a special design image, so as to improve the attention of design works. Because of the influence of Internet celebrity phenomenon, Internet celebrity design naturally inherits the gene of Internet celebrity in exchange for attention in the form of novelty and grotesque.

Internet celebrity design does not refer to a specific design style, nor does it have a unified design form. Heterogeneity of design works is an effective means to make design works quickly get attention in the face of a wide range of audience groups. The heterogeneity of works pursues the market effect and target interests, which is the product of the ultimate exertion of the social attribute of design.

\subsection{Popularization of Design Publicity}

Due to the emergence of mobile terminals, ordinary people could have a more convenient information dissemination platform, people are used to using the network to convey their views and information, so that the design of publicity towards the direction of popularization. And because of the change and upgrading of mobile terminal technology, the relationship between the two sides of design receiver and communicator is closer and the boundary is more blurry [5].

The Internet celebrity style of publicity not only effectively reduces the cost of design publicity, but also breaks the barriers between communicators and receivers. The design audience is not only the receiver of design, but also the communicator of design, which improves the audience's participation in the publicity of design works. Through the recreation and redissemination of information, the publicity effect of design increases at the speed of magnitude (see figure 4).

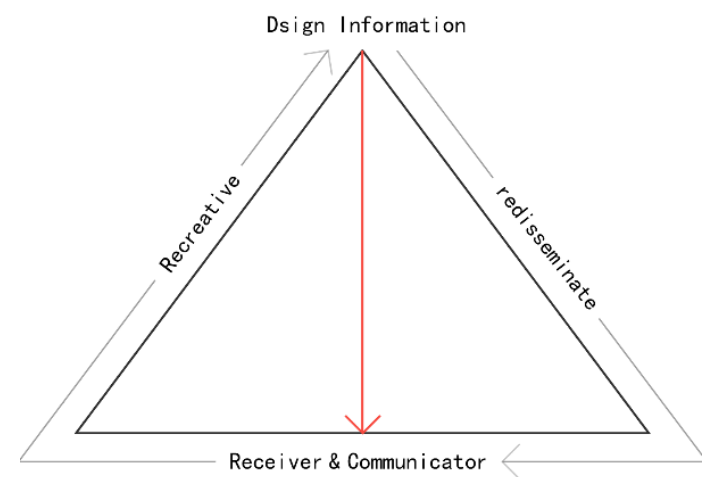

Figure 4 Design communication diagram

Common activities such as thumbs up, tweeting and following, design works use fans effect to induce the audience to actively or passively, directly or indirectly use offline and online ways to do publicity for the design. With the help of various Internet platforms and combined with their own user experience, the design information is recreated and re-disseminated, and the influence of
Internet celebrity design is snowballing under the promotion of the circulation of mass media and group effect.

\section{THE CAUSES OF INTERNET CELEBRITY DESIGN}

\subsection{The Maturity of Internet Celebrity Economy}

Internet celebrity economy refers to a business model in which network subjects gather popularity and expand influence by virtue of their own quality and individual skills through the public social platform, and then rely on their many fans to realize directional marketing, and finally transform individual symbolic value into commercial economic value [6]. Today, with the development of platform media and artificial intelligence media, the progress of media technology has pushed the capital into an unprecedented new period, and the modern communication system has greatly improved the efficiency of capital circulation [7], providing conditions for the prosperity of Internet celebrity economy. According to the calculation, the market scale of China's "net red economy" has exceeded 500 billion yuan in 2019, and it is expected that the Internet celebrity economy will reach nearly one trillion yuan in 2020 [8].

In 2019, with the vigorous development of Internet celebrity economy, Li Jiaqi, made nearly 200 million yuan. What's more surprising is that $\mathrm{Li}$ Jiaqi only advertised for five minutes for the product "spicy sausage" of the listed company JINZI ham in his live stream channel. As a result, he sold more than 100000 packages, with the total sales exceeding 3 million yuan, bringing a growth of 548 million yuan in the market value of JINZI ham, with a total of 16.77 million visitors.

The Internet celebrity economic model attracts a large number of consumers, and the huge value space it brings makes the design practitioners more and more deeply feel the influence of the Internet celebrity effect in the era of mass media. Therefore, it also makes the traditional design industry change, hoping to learn from the operation mode created by Internet celebrity economy, shape and strengthen the image of design works, capture the audience market through the identity of Internet celebrity design.

\subsection{Transformation of Communication Paradigm}

The evolution of human civilization defines the paradigm of communication, and the progress of human science and technology changes the paradigm of communication [9]. The communication paradigm is constantly updated and iterated because of the development of science and technology. With the change of communication paradigm, the traditional advertising 
mode is gradually declining. The media need to reconsider the internal connection of users, information, services and resources, and take the content as the initial connection means to establish a new type of user relationship based on mobility, scene and interaction [10].

Due to the development of the Internet and the acceleration of the pace of life and work, the highefficiency social environment has brought high-intensity work pressure, resulting in the lack of enough time and energy to focus on processing information, which makes the way of receiving and disseminating information more and more fragmented. The old communication paradigm represented by traditional advertising forms and TV media can no longer play its role in this fragmented information age. New communication paradigm based on mass media begins to appear. A large number of new generation media, such as microblog, Wechat, forum and network live broadcasting platform, rise rapidly to receive and disseminate information for the general public, and it provides a more convenient channel. Different from the previous top-down and centralized control communication paradigm dominated by human communication, mass media represents a new open and divergent communication paradigm (see figure 5).

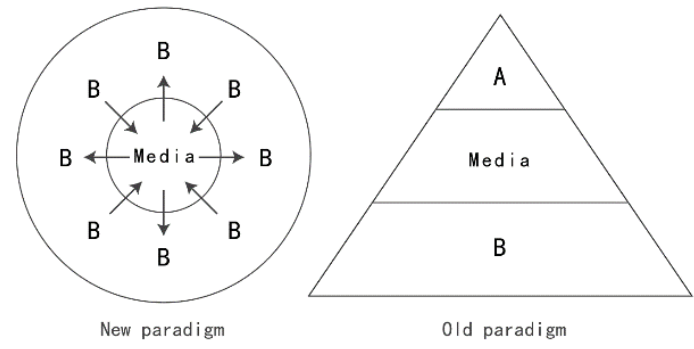

Figure 5 New and old dissemination paradigm diagram

The emergence of the new communication paradigm subverts the traditional paradigm that the official authoritative media represented by a use all kinds of media to convey information to the mass group represented by $\mathrm{B}$, which greatly reduces the threshold of communicators and enables the public to convey their views and information more efficiently. It also provides a more convenient and cheap channel for the transmission of public consumption, aesthetics, culture, values and other concepts, making it possible for mass culture such as internet celebrity to spread among the audience of all social strata.

\subsection{Change of Aesthetic Concept}

At present, aesthetics has entered an unprecedented era of democratization, with more possibilities and richness. Under the double attack of new technology and new cultural connotation, the concept of "Aesthetics" and "Aesthetic behavior" in the classic or traditional perspective have changed [11]. Aesthetic concept has changed from "Meaningful form" by Clive bell (18811964) to an eye-catching form, and aesthetic behavior has changed from "Pleasure or unhappiness without any interest" by Immanuel Kant (1724-1804) to an aesthetic activity with both benefit and obvious purpose.

Compared with traditional aesthetics, popular aesthetics pays more attention to people's self-expression and pursues uniqueness and difference. People's aesthetic tolerance has also been greatly improved, in the face of the emotion and desire expressed in the aesthetic process is no longer ignored. From the point of view of the social attribute of design, the aesthetic concepts and values conveyed by internet celebrity to the public are bound to be reflected in contemporary design works. In the face of this aesthetic change, if the design works want to be sought after by the public and become internet celebrity design, whether the design practitioners agree with the public's aesthetic concept or not, they also need to create design works that meet the audience's aesthetic needs in addition to the basic functions.

\subsection{Prevalence of Consumerism}

In recent years, stable economic growth has accumulated a lot of social capital, according to the annual GDP and total retail sales of social consumer goods data released by the National Bureau of Statistics (see figure 6). In 1978, the gross domestic product was only 367.9 billion yuan, and then leaped continuously. By 2019 , the gross domestic product is close to 100 trillion yuan. With the rapid development of the national economy, people's demand for consumption has also increased significantly. Compared with 1978, the total retail sales of social consumer goods in 2019 has increased by an amazing 283 times.

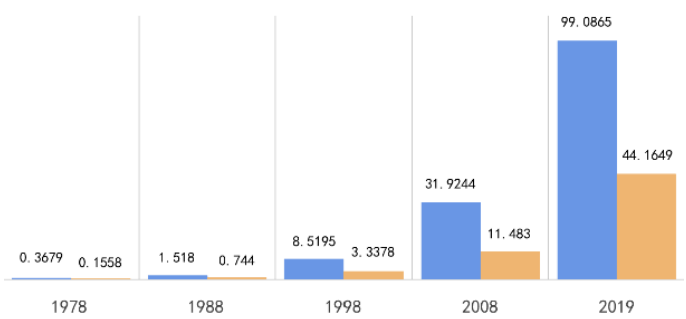

Figure 6 1978-2019 China's GDP and total retail sales of consumer goods (unit: trillion yuan)

The long-term lack of capital has been met in just a few decades. With the completion of living infrastructure, people's living standards and living environment have been greatly improved. The great richness of material life makes people's values change and gradually tend to materialism. In such an environment, people's consumption behavior is "alienated" and take consumption conduct as their own consumption purpose [12]. Under the double pressure of life and work in modern society, a large number of people 
take consumption as a way to realize their own value, which has become a way of self comfort for people to lose freedom and escape from reality in their working life [13]. To sum up, people are not actually consuming things themselves, but "expressing their will through things", and use things as meaning symbols to highlight their own personality [14].

A large number of consumers have injected a steady stream of power into social production. A wide range of goods are flooding the market, leading to the corresponding increase of market competition. How to make their own design stand out in the vast number of commodities and be favored by consumers is a problem that contemporary designers need to face. As an effective means to establish a unique brand image and attract consumers, internet celebrity design, which is good at using novel and weird formal language to capture attention, provides an answer for design practitioners on how to make their works more popular so as to win more consumers. Because of this, a large number of Internet celebrity flaunting the design from the overwhelming hit.

\section{CONCLUSION}

Since its birth, internet celebrity design has swept every design field with a hurricane speed, becoming a highly concerned social phenomenon. The design audience has quickly formed two camps with clear boundaries. The positive side thinks that internet celebrity design reflects the needs of the new era, and represents the new direction of fashion; the rise of Internet celebrity design is viewed from the point of view of vulgar, alternative and evil taste by the negative side. In fact, one-sided positive and one-sided negative cannot fully cover the real situation. Excessive optimism ignores the tendency of internet celebrity design to pursue internet celebrity effect due to excessive pursuit of marketization and even at the expense of the value of the design itself. Blindly pessimistic, we only see the kitsch culture in the narrow sense of internet celebrity, but fail to see the popularity of internet celebrity design (especially the emergence of new communication paradigm) has a positive impact on the design industry.

The rapid proliferation of the negative side design in this era is determined by the discipline characteristics of design itself. As a useful art, design is composed of two parts: social attribute and artistic attribute. These two attributes determine that if the design works want to be promoted among the audience to the maximum extent and realize the maximization of interests, the design practitioners should not only consider the social attribute when they are engaged in design activities, the design value of the work should also meet the needs of the target audience. The emergence of the negative side design is the result of the interaction of social, cultural, economic, technological and other reasons. Just like the prevailing trend of stylism, pop art, Dadaism and so on, it is a different response to different times. With the advent of 5G technology, the fast-food way of information acquisition will inevitably become the mainstream in this information "Big Bang" era. Internet celebrity design can effectively capture the attention of the audience by virtue of its own uniqueness and differential performance. However, in order to extend the time limit of design and maintain the internet celebrity status of design, in addition to its novel and unique forms of expression, it also needs to excavate the design itself such as the connotation and value of the concept.

\section{REFERRENCES}

[1] Sun Yu-xuan. The development process, social influence and development trend of online popularity [J]. Audiovisual, 2019 (07): 180-181.

[2] Wang Yan, Shi Qing, HU De-jun. The characteristics of Internet popularity from the perspective of aesthetic culture [J]. Journal of Social Sciences, Harbin Normal University, 2017,8 (02): 162-165.

[3] Xian Yi. The 600 year old Palace Museum has become a "Internet celebrity" [J]. World knowledge pictorial (art perspective), 2017 (07): 4-7.

[4] Chen Yun-feng, Shen Meng-tang,WANG Xi-ning,et al. An analysis of the research status and development trend of "internet celebrities" -quantitative content analysis based on literature [J]. Journal of Hubei Institute of Technology (humanities and social science), 2020,37 (04): 73-76 +86 .

[5] Min Jie, Li Peng, Liu Jian-wei. On contemporary art language forms in design [J]. Packaging engineering, 2019,40 (10): 276-282.

[6] WANG Jin-wen. ZHANG Jun. The symbolic logic of individual behavior in consumer society: Sociological Analysis of "Internet red economy" [J]. Journal of Changchun University of Technology (social science edition), 2019,32 (04): 62-67.

[7] HU Yi-qing. Perspective on "planting grass and bringing goods": Based on the perspective of political economy of communication [J]. Journal of Northwest Normal University (social science edition), 2020,57 (05): 29-36.

[8] Ge Jing-jing. Internet celebrity economy is booming [J]. China information circles, 2020 (05): 22-25.

[9] YU Ming-yang. Science and technology restructures communication paradigm [J]. News and communication review, 2020, 73 (05): 1.

[10] LUO Jing. Transmutation of ecological evolution redefining media business model[J]. Media observation, 2020 (10): 88-93. 
[11] HOU Li-you-mei. "We Media" era of aesthetic status quo and thinking $[\mathrm{J}]$. Journal of Dalian University of Technology (social science edition), 2018,39 (01): 124-128.

[12] LI Jin-kang. A review of the impact of materialism on consumption alienation $[\mathrm{J}]$. Modern communication, 2020 (15): 252-254.

[13] Wei Shu-yi. Analysis of China's consumption status based on Western Marxist consumption alienation theory $[\mathrm{J}]$. Journal of Shandong Radio and Television University, 2020 (04): 50-53.

[14] Cao Dong-bo. What do we consume when we consume [N]. Article collection journal, 2020-01-03 (W10). 